\title{
The Effects of Solvents and Solid-to-Solvent Ratios on Ultrasound-Assisted Extraction of Carotenoids from Chlorella vulgaris
}

\author{
Dianursanti ${ }^{1 *}$, Aisyah Razaanah Siregar ${ }^{1}$, Yoshiaki Maeda ${ }^{2}$, Tomoko Yoshino ${ }^{2}$, \\ Tsuyoshi Tanaka² \\ ${ }^{1}$ Bioprocess Engineering Study Program, Department of Chemical Engineering, Faculty of Engineering, \\ Universitas Indonesia, Kampus UI Depok, Depok 16424, Indonesia \\ ${ }^{2}$ Division of Biotechnology and Life Sciences, Institute of Engineering, Tokyo University of Agriculture and \\ Technology, 2-24-16, Naka-cho, Koganei, Tokyo 184-8588, Japan
}

\begin{abstract}
Research around using algae as a natural source of carotenoids has been intense in the 21st century, given the wide applications of carotenoids in the pharmaceutical, health, and food industries. This study aimed to get the highest yield of carotenoids from Chlorella vulgaris by ultrasound extraction. This study evaluated two parameters: the extraction solvent (ethanol, acetone, and diethyl ether were tested) and the solid-to-solvent ratio (1:30, 1:50, and 1:100 were tested). The carotenoid extracted from $C$. vulgaris was lutein, and its compounds were identified by UV-Vis spectroscopy. The highest carotenoid yield was achieved using ethanol at $1.146 \pm 0.082 \mathrm{mg} / \mathrm{g}$ and a solid-to-solvent ratio of 1:100 (g/mL). This research shows the use of a specific extraction solvent along with a solid-to-solvent ratio is significant to determine carotenoids yield desired. Further study of other parameters (e.g., temperature and ultrasound intensity) is necessary for the optimum extraction condition.
\end{abstract}

Keywords: Carotenoids; Chlorella vulgaris; Lutein; Ultrasound extraction; Solvent extraction

\section{Introduction}

Carotenoids are pigments synthesized in plants and microorganisms to give them a yellow orange to red color. The carotenoids function alongside chlorophyll to absorb light energy in photosynthesis, maintain the structure and function of photosynthesis, and anticipate excess energy (Saini \& Keum, 2018). Carotenoids have antioxidant functions caused by long polyene chains, which have 35-40 carbon atoms (Chandi and Gill, 2011). Because of their antioxidant properties, carotenoids are used in the pharmaceutical and health fields to reduce the risk of certain cancers and cardiovascular diseases, stimulate the immune response, and hamper cataract, and atherosclerotic development (AlvesRodriguez and Shao, 2004). Moreover, carotenoids from Chlorophyta are important natural food colorants and additives as they have high nutritional values and are source of proteins, carbohydrates, lipids, and vitamins (Christaki et al., 2015).

Research around using utilization as a natural source of carotenoids has been very intensive in the $21^{\text {st }}$ century. Microalgae, especially Chlorella, are alternative and sustainable sources of various bioactive natural carotenoids, including $\beta$-carotene, lutein,

${ }^{*}$ Corresponding author's email: dianursanti@ui.ac.id, Tel.: +62-811-1921-565; Fax: +62-21-7863515 doi: 10.14716/ijtech.v11i5.4331 
astaxanthin, zeaxanthin, violaxanthin, and fucoxanthin (Cha et al., 2008; Machmudah and Goto, 2013). Carotenoids produced by microalgae are commonly found in chloroplasts and bound to membranes and other macromolecules in the intracellular system. The cell wall and membrane surrounding the cell become barriers that limit the rate of mass transfer of the carotenoids during extraction, so carotenoid extraction requires disruption of cell walls, plasma membranes, and chloroplasts (Poojary et al., 2016). Carotenoids are easily damaged and degraded by exposure to light, heat, and oxygen. Therefore, extraction methods must be considered that reduce or eliminate these harmful effects (Mertz et al., 2010; Aflaki, 2012; Machmudah and Goto, 2013; Mäki-Arvela et al., 2014; Mulia et al., 2018; Saini and Keum, 2018).

Chlorella vulgaris is used as a source of carotenoid compounds because it has the highest total content compared to the other Chlorophyta microalgae (Chandi and Gill, 2011). The most-used techniques to extract carotenoid compounds from $C$. vulgaris in recent years have been maceration, sonication, Soxhlet, and pressurized liquid extraction (PLE) (Machmudah and Goto, 2013; Mäki-Arvela et al., 2014; Saini and Keum, 2018). Ultrasound extraction has been reported to be an economical method for carotenoid extraction because it requires less energy and solvent, which damaging carotenoid content because of light, heat, or oxygen (Cha et al., 2010). Increasing the extraction yield from ultrasound treatment comes from cavitation, which facilitates the disruption of the cell wall by the ultrasound waves (Mäki-Arvela et al., 2014). Moreover, the carotenoid yield from C. vulgaris by ultrasound extraction was higher than from maceration, Soxhlet extraction, and PLE (Cha et al., 2010).

The objective of this study was to increase the yield of carotenoids by testing two parameters and to provide a new set of data on the optimum conditions for extracting carotenoids from $C$. vulgaris. To achieve those results, three solvents with various polarities (ethanol, acetone, and diethyl ether) and three solid-to-solvent ratios (1:30, 1:50, and 1:100) were tested. Using a solvent to extract carotenoids depends on whether carotenoids are polar or non-polar (Cha et al., 2010; Machmudah and Goto, 2013; Mäki-Arvela et al., 2014; Mulia et al., 2015; Othman et al., 2017). A previous study also showed that the increase of solid-to-solvent ratio in the extraction on carotenoids from pumpkin resulted in a significant increase in carotenoid content (Shahidan et al., 2017). Thus, the present study is expected to achieve increased yields of carotenoids by varying the parameters being tested. It is also expected to provide a new set of data on the optimum conditions for carotenoid extraction from C. vulgaris. The extract of carotenoids was found to be optimized at a 1:100 solid-tosolvent ratio by using ethanol.

\section{Methods}

C. vulgaris strain C27 was obtained from Tokyo University of Agriculture and Technology. C. vulgaris was cultured in 48 -well plates and stored at $-80^{\circ} \mathrm{C}$ until used. The ethanol, acetone, diethyl ether, and $n$-hexane used were analytical grade $(>96.0 \%)$ from Fujifilm Wako Pure Chemical Corporation, Japan. Distilled water and ultrapure water were obtained from Milli-Q Reference Water Purification System, Fisher Scientific. The detail of the research method used in this paper is shown in Figure 1. 


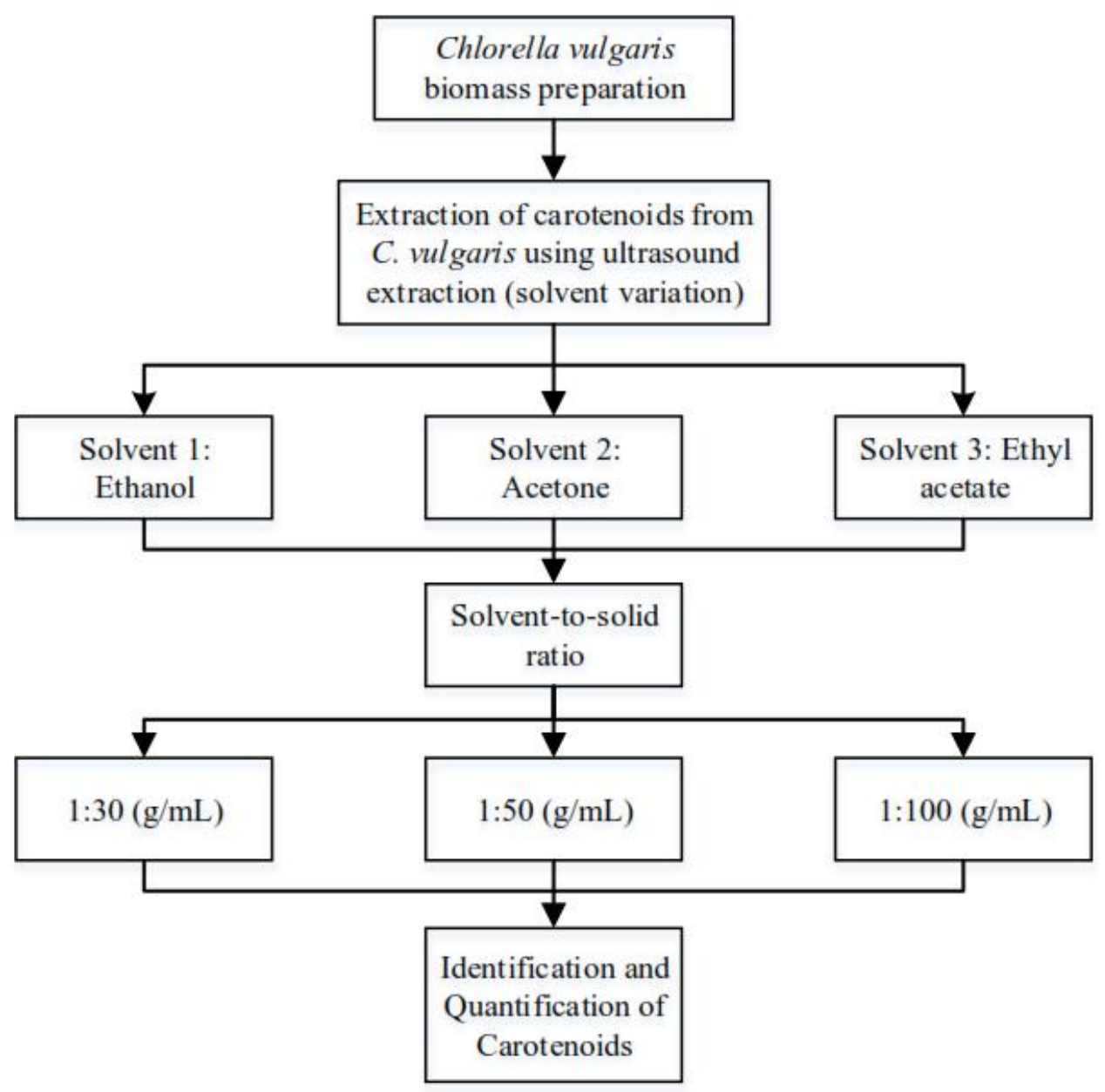

Figure 1 General scheme of research method

\subsection{Preparation of C. vulgaris Biomass}

C. vulgaris cultures in 48-well plates were maintained regularly under laboratory conditions at $24^{\circ} \mathrm{C}\left( \pm 1^{\circ} \mathrm{C}\right)$. Cultures were incubated in photobioreactor using the following conditions; BBM medium, temperature $24^{\circ} \mathrm{C}\left( \pm 1^{\circ} \mathrm{C}\right)$, light intensity $80 \mu \mathrm{mol}$ photons $\mathrm{m}-2 \mathrm{~s}$ 1 , airflow rate $0.4 \mathrm{~L} / \mathrm{min}, \mathrm{CO}_{2}$ concentration $2 \%$, and $24 \mathrm{~h}$ light cycle. Cells of $C$. vulgaris were harvested after 11 days of cultivation in the photobioreactor. All the microalgae cells were harvested and freeze-dried to get a powdered form of $C$. vulgaris biomass, which was stored at $-20^{\circ} \mathrm{C}$.

\subsection{Extraction of Carotenoids from C. vulgaris}

\subsubsection{Ultrasound extraction}

The extraction of carotenoids was begun by rehydrating $0.1 \mathrm{~g}$ of powdered freeze-dried C. vulgaris with $1 \mathrm{~mL}$ of distilled water and $10 \mathrm{~mL}$ of organic solvent. Then the rehydrated mixture was sonicated in an ultrasonic cleaning bath (HONDA W-170-ST, Japan) at room temperature in the dark for 2 hours. The extraction mixture was vortexed after 2 hours with Vortex-Genie 2 (Scientific Industries) and it was centrifuged for 20 minutes at 1,500 rpm using low-speed centrifuge (TOMY LC-121, Japan). The supernatant layer was collected for purification of carotenoids, and the remaining pellet residue was extracted repeatedly until it contained no trace of carotenoids.

The organic solvents used in this experiment were ethanol, acetone, and diethyl ether. These variations were determined by choosing solvents with different ranges of polarity. 
The second variation used in this experiment was the solid-to-solvent ratio, at levels of 1:30, $1: 50$, and 1:100 (biomass weight in $\mathrm{g}$ and solvent volume in $\mathrm{mL}$ ).

\subsubsection{Saponification and partition of carotenoids}

Saponification was carried out by adding $240 \mu \mathrm{L}$ of $100 \% \mathrm{KOH}$ to $10 \mathrm{~mL}$ mixture at room temperature and in the dark. After saponification for 1 hour in the dark, $6 \mathrm{~mL}$ of hexane was added to partition carotenoids. This mixture was shaken for $1 \mathrm{~min}$ and then diluted with $6 \mathrm{~mL}$ of water. Partition was carried out in an amber separatory funnel until the two phases (organic phase and aqueous phase) had clearly separated. The extract from the upper layer containing carotenoids was then collected and tested with UV-Vis spectroscopy analysis.

\subsection{Characterization and Quantification of Carotenoids from C. vulgaris}

Carotenoid extracts from C. vulgaris were identified using UV-Vis spectral characteristics and compared to data available in the literature. The identification used UVVis spectrophotometry (Shimadzu UV-Vis Spectrophotometry 1800, Japan) at wavelengths of $300 \mathrm{~nm}$ to $600 \mathrm{~nm}$ wavelengths to get UV spectra of purified lutein based on wavelengths of maximum absorption and fine spectral structure. The concentration of total carotenoid extract (mg/g biomass) was determined by measuring the absorbance of the samples at $445 \mathrm{~nm}$, then it was calculated using the following equation (de Carvalho et al., 2012):

$$
\text { Carotenoids content }(\mu \mathrm{g} / \mathrm{g})=\frac{\mathrm{A} \times \mathrm{V}(\mathrm{mL}) \times 10^{4}}{\mathrm{~A}_{1 \mathrm{~cm}}^{1 \%} \times \mathrm{P}(\mathrm{g})}
$$

where $\mathrm{A}$ is absorbance, $\mathrm{V}$ is total extract volume, $\mathrm{P}$ is sample weight, and $\mathrm{A}_{1 \mathrm{~cm}}^{1 \%}$ is the extinction coefficient of lutein in organic solvents (2480 for diethyl ether, 2540 for acetone, and 2550 for ethanol).

\subsection{Calculation: Specific Growth Rate, Biomass Productivity, and Carotenoid Productivity}

The specific growth rate $(\mu)$ was calculated from the measured cell concentration using the following equation (Nguyen et al., 2019):

$$
\mu\left(\text { day }^{-1}\right)=\frac{\ln \left(N_{2} / N_{1}\right)}{t_{2}-t_{1}}
$$

where $N_{1}$ is the cell density (cells $/ \mathrm{mL}$ ) at time $t_{1}, N_{2}$ is the cell density at $t_{2}, t_{1}$ is the time of initial culture (day), $t_{2}$ is the time of final culture (day).

Biomass productivity in the volumetric unit $\left(Q_{x}\right)$ was calculated using the following equation (Araya et al., 2014):

$$
Q_{x}\left(\mathrm{gL}^{-1} \mathrm{day}^{-1}\right)=\frac{x_{f}-x_{0}}{t_{f}-t_{0}}
$$

where $x_{f}$ is the final biomass concentration at the end of cultivation at $t_{f}$, and $x_{0}$ is the initial biomass concentration at $t_{0}$.

Carotenoid productivity in volumetric unit corresponds to the product $Q_{x} \cdot y$, where $y$ stands for intracellular carotenoid content (mg carotenoids/g biomass) (Araya et al., 2014). 


\section{Results and Discussion}

\subsection{C. vulgaris Growth}

Figure 2 shows the growth curve and the specific growth curve of $C$. vulgaris for the 11 days after cultivation. From the growth curve, it can be concluded that the cultures undergo three growth phases: the lag phase, the exponential phase, and the stationary phase. The lag phase happened during the first two days of cultivation, followed by the exponential phase for eight days of cultivation. During the lag phase, the specific growth rate of $C$. vulgaris increased until the third day of cultivation. $C$. vulgaris cells achieved the stationary phase in the last day of cultivation, resulting in a significant decrease in specific growth rate, as shown in Figure $2 \mathrm{~b}$. The result of this study follows the result of previous research in various Chlorella species tested had a lag phase of approximately two days and reached the exponential phase in 4-6 days of cultivation in BBM medium (Sharma et al., 2016).

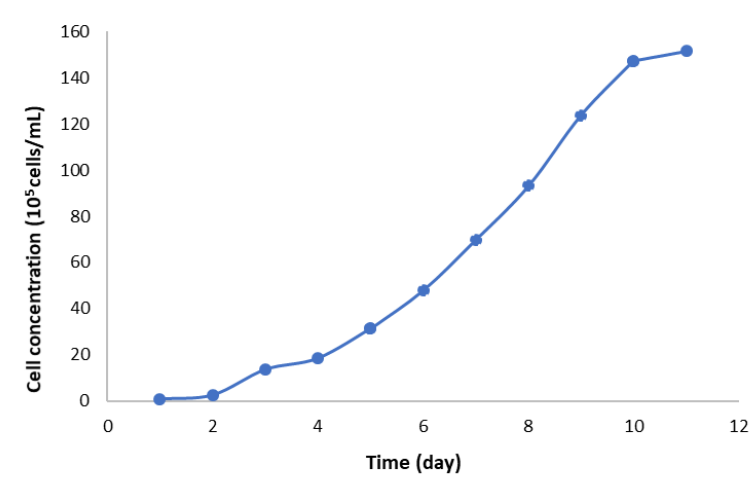

(a)

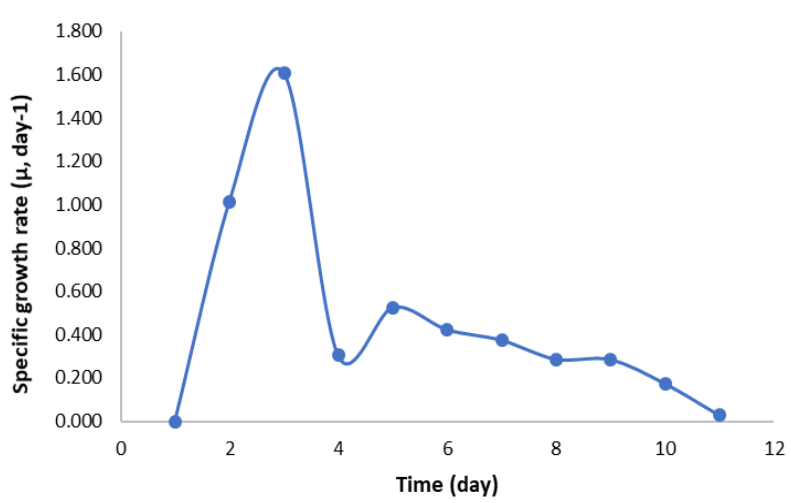

(b)

Figure 2 (a) Growth curve of $C$. vulgaris; (b) Specific growth curve of $C$. vulgaris

The biomass concentration dry weight of $C$. vulgaris in the BBM medium was $1.041 \pm 0.153 \mathrm{~g} / \mathrm{L}$. The biomass productivity was $0.095 \pm 0.014 \mathrm{~g} / \mathrm{L} / \mathrm{day}$, and the specific growth was 0.5 day $^{-1}$. This result correlates with findings from studies of the effect of light intensity on the growth of $C$. vulgaris biomass; 0.36 day $^{-1}$ (Nguyen et al., 2019), 0.65 day $^{-1}$ (Araya et al., 2014), 1.0-1.24 day-1 (McClure et al., 2019). Those studies showed a specific increase in the growth rate with respect to light intensity (Araya et al., 2014; Nguyen et al., 2019; McClure et al., 2019). These results occurred because the light energy provided was higher than the minimum energy needed for photosynthesis for each cell. Thus, the photosynthesis rate was higher than the respiration rate, and it led to an increase in cell concentration (Danesi et al., 2011; Dianursanti et al., 2016). However, McClure et al. (2019) found that increasing the light intensity led to a decrease in the specific lutein concentration at intensities above $160 \mu \mathrm{mol}$ photons $\mathrm{m}^{-2} \mathrm{~s}^{-1}$ (McClure et al., 2019).

\subsection{Characterization of Carotenoid from C. vulgaris}

The extracted carotenoids were identified by UV-Vis Spectrophotometry Shimadzu 1800 and UV Probe 2.3.1 software. The UV spectrum results are shown in Figure 3. The UV spectra of the carotenoids extracted by ultrasound from $C$. vulgaris showed the wavelengths of maximum absorption at values of $422 \mathrm{~nm}, 447 \mathrm{~nm}$, and $475 \mathrm{~nm}$, and a spectral fine structural value (\%III/II) of 62. These values showed that the carotenoid contained in $C$. vulgaris was lutein, based on the maximum absorption wavelength at $422 \mathrm{~nm}, 445 \mathrm{~nm}, 474$ $\mathrm{nm}$, and spectral fine structures (\%III/II) value of 60 (Rodriguez-Amaya and Kimura, 2004). 


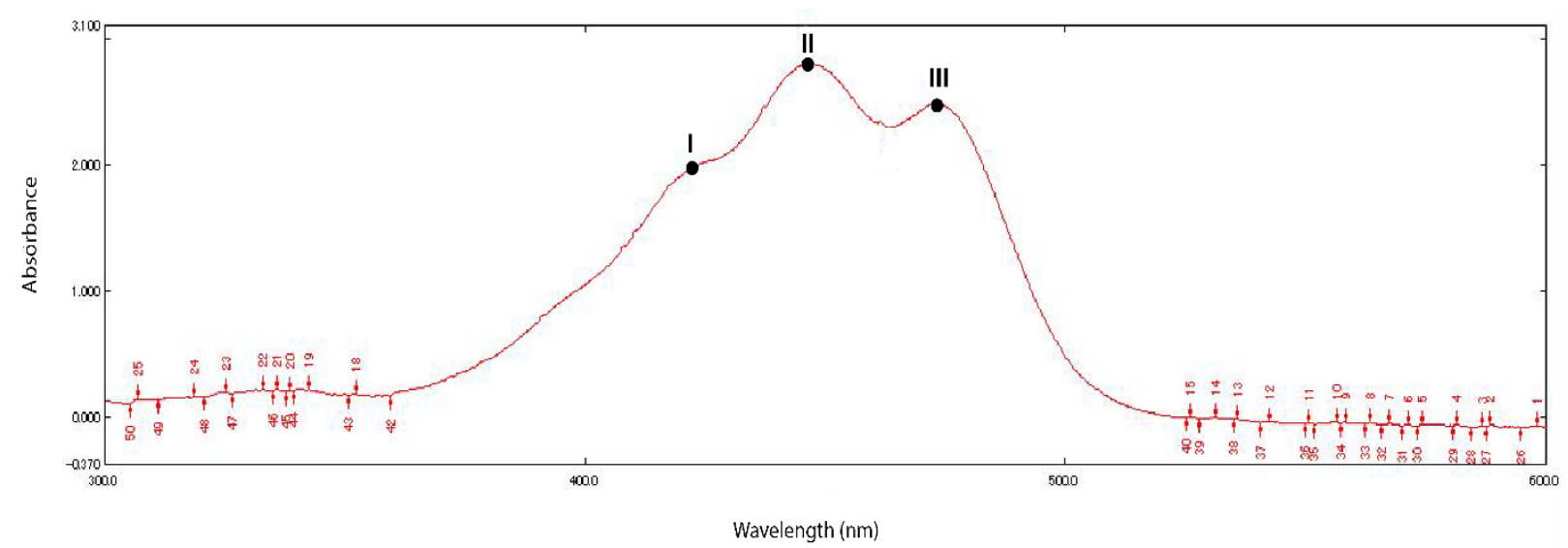

Figure 3 UV Spectra of the purified carotenoid from C. vulgaris extracted by ultrasound

Furthermore, this UV spectrum result agreed with Cha et al. (2008), who reported that the carotenoids from $C$. vulgaris were almost completely composed of lutein (Cha et al., 2008). Moreover, UV-Vis spectra from the present findings were similar to the results from previous work that used the same method (Deenu et al., 2013).

\subsection{Effect of Various Solvent on Carotenoids Extraction from C. vulgaris}

Figure 4 shows the carotenoid yields from the three solvents tested. The results showed that ethanol produced the highest yield of total carotenoids, at $0.789 \pm 0.08 \mathrm{mg} / \mathrm{g}$ and a carotenoid productivity of $0.075 \pm 0.008 \mathrm{mg} / \mathrm{L} /$ day. This result is significantly higher than those obtained using diethyl ether, namely $0.380 \pm 0.087 \mathrm{mg} / \mathrm{g}(\mathrm{p}<.003)$. Moreover, the results from using ethanol were higher than those from acetone, which had carotenoid yields of $0.610 \pm 0.077 \mathrm{mg} / \mathrm{g}(\mathrm{p}<.05)$. Different extraction solvents caused different yields of total carotenoids. The relative polarity of diethyl ether, acetone, and ethanol are respectively $0.117,0.355$, and 0.654 (Reichardt, 2003). Therefore, diethyl ether, which has the lowest polarity among the solvents, had the lowest result for total carotenoid extraction.

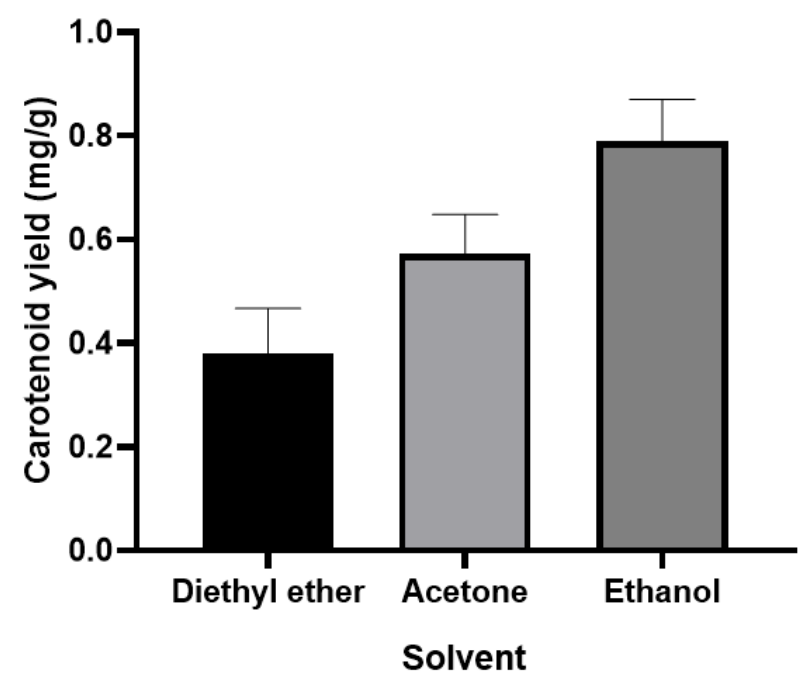

Figure 4 Carotenoid yields from ultrasound extraction from C. vulgaris for three solvents. Data are the mean \pm standard deviation (STDEV) of three independent experiments

The effectiveness of carotenoid extraction is determined by the ability of a solvent to dissolve carotenoids based on their natural properties, and this ability depends on the polarity of the solvent (Warkoyo and Saati, 2011). Carotenoid have different cosolubilization properties that depends on the polarity of the solvent. Non-polar carotenoids 
such as $\beta$-carotene are more soluble in non-polar solvents, whereas polar carotenoids, such as lutein, show higher solubility in polar solvents (Rivera and Canela, 2012). Based on the characterization of carotenoids, $C$. vulgaris is mainly composed of polar carotenoid (lutein). Thus, the results of this study are in accordance with the theory of carotenoid cosolubilization.

Herrero et al. (2006) reported that ethanol gave the highest yield for medium antioxidant activities when used for extraction from microalgae with high water-soluble content (Herrero et al., 2006). Moreover, Cha et al. (2010) reported that a medium of $90 \%$ ethanol increased the yield of carotenoid extraction by $50 \%$ compared with extraction with acetone. Therefore, the high efficiency of extracting carotenoids from $C$. vulgaris using ethanol comes from caused by the high hydrophilic content, which is around $63 \mathrm{~g}$ of protein for every $100 \mathrm{~g}$ of dry cell weight of Chlorella (Cha et al., 2010). Ethanol is also considered to be a food-grade solvent, so it has lower toxicity than other types of alcohol solvent, and it has been shown to prevent toxic residues that occur when acetone is used (Calo et al., 1995; Aflaki, 2010). Based on this consideration, ethanol is used as an extraction solvent when studying the effects of solid-to-solvent ratios on ultrasound extraction.

\subsection{Effects of the Solid-to-solvent Ratio on Carotenoids Extraction from C. vulgaris}

Figure 5 shows the results for carotenoid yields from the three solid-to-solvent ratios tested. The results showed that the yield of lutein increased significantly $(p<.05)$ as the volume of solvent increased of solvent volume. The carotenoid quantification showed that solid-to-solvent ratio 1:100 provided the highest yield of total carotenoids at $1.146 \pm 0.082$ $\mathrm{mg} / \mathrm{g}$ with carotenoid productivity of $0.109 \pm 0.008 \mathrm{mg} / \mathrm{L} /$ day. The increase in carotenoid yield is caused by the increases in the concentration gradient and the rate of diffusion. This finding applies to mass transfer principles that state that the driving force for mass transfer is the concentration gradient, thus allowing a higher extraction of solids by solvent (Tan et al., 2011).

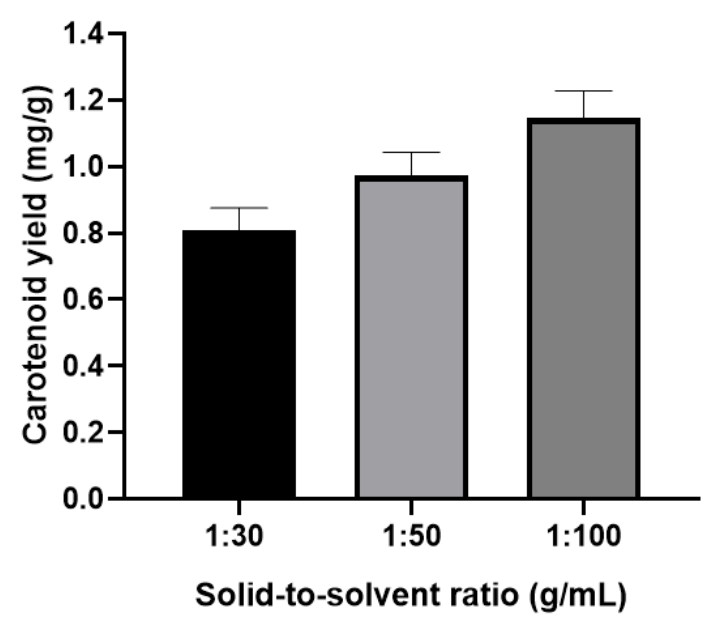

Figure 5 Carotenoid yield by ultrasound extraction from C. vulgaris at three solid-to-solvent ratios. Data are the mean \pm standard deviation (STDEV) of three independent experiments

In ultrasound extraction, cell walls are damaged by ultrasound waves, which results in a greater contact surface area between the solid and liquid phases (Deenu et al., 2013). The rate of extraction increased when the higher solid-to-solvent ratio provided a higher concentration gradient between internal and external surfaces of the dissolved carotenoids (Shi et al., 2002). Besides, diffusion transfer between solid and solvent is caused by the random movement of molecules, with the concentration gradient as the driving force (Lebovka et al., 2011). The increase of extraction solvent increases the carotenoid content 
up to the equilibrium point. Once that point is reached, any increase of solvent volume does not affect the carotenoid content (Bera and Das, 2013). To achieve the equilibrium condition, there must be a further extension of the solid-to-solvent ratio (e.g., 1:120, 1:150, 1:200) for carotenoids extraction from $C$. vulgaris by ethanol.

\section{Conclusions}

The results of the present study show that different solvents and different solid-tosolvent ratios vary the carotenoid yield from $C$. vulgaris by ultrasound extraction. It shows that ethanol is a better extraction solvent than diethyl ether or acetone. The highest carotenoid yield was achieved using ethanol as the extraction solvent and a solid-to-solvent ratio of 1:100 $(\mathrm{g} / \mathrm{mL})$. For further study, we recommend optimizing this extraction method by testing extraction under other conditions, such as differences in temperature, duration, ultrasound intensity, and ultrasound frequency.

\section{Acknowledgements}

The authors would like to thank Tanaka, Arakaki \& Yoshino Laboratory, Biomolecular Engineering \& Marine Biotechnology, Department of Biotechnology and Life Sciences, Tokyo University of Agriculture and Technology, for their research facilities and JASSO (Japan Student Service Organization) and PUTI for providing financial aid for this research.

\section{References}

Aflaki, N., 2012. Optimization of Carotenoid Extraction in Peel and Flesh of Cantaloupe (Cucumis melo L.), with Ethanol Solvent. Master's Thesis, Graduate Program, Laval University, Quebec, Canada

Alves-Rodrigues, A., Shao, A., 2004. The Science Behind Lutein. Toxicology Letters, Volume 150, pp. $57-83$

Araya, B., Gouveia, L., Nobre, B., Reis, A., Chamy, R., Poirrier, P., 2014. Evaluation of the Simultaneous Production of Lutein and Lipids using a Vertical Alveolar Panel Bioreactor for Three Chlorella Species. Algal Research, Volume 6(B), pp. 218-222

Bera, D., Das, S., 2013. Mathematical Model Study on Solvent Extraction of Carotene from Carrot. International Journal of Research in Engineering and Technology, Volume 2(09), pp. 343-349

Calo, P., Velazquez, J.B., Sieiro, C., Blanco, P., Longo, E., Villa, T.G., 1995. Analysis of astaxanthin and other carotenoids from several Phaffia rhodozyma mutants. Journal of Agricultural and Food Chemistry, Volume 43(5), pp. 1396-1399.

Cha, K.H., Koo, S.Y., Lee, D.U., 2008. Antiproliferative Effects of Carotenoids Extracted from Chlorella ellipsoidea and Chlorella vulgaris on Human Colon Cancer Cells. Journal of Agricultural and Food Chemistry, Volume 56(22), pp. 10521-10526

Cha, K.H., Lee, H.J., Koo, S.Y., Song, D.G., Lee, D.U., Pan, C.H., 2010. Optimization of Pressurized Liquid Extraction of Carotenoids and Chlorophylls from Chlorella vulgaris. Journal of Agricultural and Food Chemistry, Volume 58(2), pp. 793-797

Chandi, G.K., Gill, B.S., 2011. Production and Characterization of Microbial Carotenoids as an Alternative to Synthetic Colors: A Review. International Journal of Food Properties, Volume 14(3), pp. 503-513

Christaki, E., Bonos, E., Florou-Paneri, P., 2015. Innovative Microalgae Pigments as Functional Ingredients in Nutrition. In: Handbook of Marine Microalgae. Christaki et al., Academic Press, Elsevier, London, pp. 233-243 
Danesi, E.D.G., Rangel-Yagui, C.O., Sato, S., de Carvalho, J.C.M., 2011. Growth and Content of Spirulina platensis Biomass Chlorophyll Cultivated at Different Values of Light Intensity and Temperature using Different Nitrogen Sources. Brazilian Journal of Microbiology, Volume 42(1), pp. 362-373

de Carvalho, L.M.J., Gomes, P.B., de Oliviera Godoy, R.L., Pacheco, S., do Monte, P.H.F., de Carvalho, J.L.V., Nutti, M.R., Neves, A.C.L., Vieira, A.C.R.A., Ramos, S.R.R., 2012. Total Carotenoid Content, A-Carotene and ß-Carotene, of Landrace Pumpkins (Cucurbita moschata Duch): A Preliminary Study. Food Research International, Volume 47(2), pp. 337-340

Deenu, A., Naruenartwongsakul, S., Kim, S.M., 2013. Optimization and Economic Evaluation of Ultrasound Extraction of Lutein from Chlorella vulgaris. Biotechnology and Bioprocess Engineering, Volume 18, pp. 1151-1162

Dianursanti., Santoso, A., Delaamira, M., 2016. Utilization of Chlorella vulgaris to Fixate a High Concentration of Carbon Dioxide in a Compost-based Medium. International Journal of Technology, Volume 7(1), pp. 168-175

Herrero, M., Jaime, L., Martin-Alvarez, P.J., Cifuentes, A., Ibanez, E., 2006. Optimization of the Extraction of Antioxidants from Dunaliella salina Microalga by Pressurized Liquids. Journal of Agricultural and Food Chemistry, Volume 54(15), pp. 5597-5603

Lebovka, N., Vorobiev, E., Chemat, F., 2011. Enhancing Extraction Processes in the Food Industry. $1^{\text {st }}$ Edition. New York, USA: CRC Press

Machmudah, S., Goto, M., 2013. Methods for Extraction and Analysis of Carotenoids. In: Natural Products. Springer-Verlag Heidelberg, Berlin, Germany pp. 3367-3411

Mäki-Arvela, P., Hachemi, I., Murzin, D.Y., 2014. Comparative Study of the Extraction Methods for Recovery of Carotenoids from Algae: Extraction Kinetics and Effect of Different Extraction Parameters. Journal of Chemical Technology \& Biotechnology, Volume 89(11), pp. 1607-1626

McClure, D.D., Nightingale, J.K., Luiz, A., Black, S., Zhu, J., Kavanagh, J.M., 2019. Pilot-Scale Production of Lutein using Chlorella Vulgaris. Algal Research, Volume 44, pp. 1-12

Mertz, C., Brat. P., Caris-Veyrat, C., Gunata, Z., 2010. Characterization and Thermal Lability of Carotenoids and Vitamin C of Tamarin Fruit (Solanum betaceum Cav.). Food Chemistry, Volume 119, pp. 653-659

Mulia, K., Adam, D., Zahrina, I., Krisanti, E.A., 2018. Green Extraction of Palmitic Acid from Palm Oil using Betaine-based Natural Deep Eutectic Solvents. International Journal of Technology, Volume 9(2), pp. 335-344

Mulia, K., Krisanti, E., Maulana, T., Dianursanti., 2015. Selective Polarity-guided Extraction and Purification of Acetogenins in Annona muricata L. Leaves. International Journal of Technology, Volume 6(7), pp. 1221-1227

Nguyen, T.D.P., Nguyen, D.H., Lim, J.W., Chang, C-K., Leong, H.Y., Tran, T.N.T., Vu, T.B.H., Nguyen, T.T.C, Show, P.L., 2019. Investigation of the Relationship between Bacteria Growth and Lipid Production Cultivating of Microalgae Chlorella vulgaris in Seafood Wastewater. Energies, Volume 12(12), pp. 1-12

Othman, R., Noh, N., Nurrulhidayah, A.F., Anis Hamizah, H., Jamaludin, M.A., 2017. Determination of Natural Carotenoids Pigments from Fresh Water Green Algae as Potential Halal Food Colorants. International Food Research Journal, Volume 24 (Suppl), pp. S468-S471

Poojary, M.M., Barba, F.J., Aliakbarian, B., Donsi, F., Pataro, G., Dias D.A., Juliano, P., 2016. Innovative Alternative Technologies to Extract Carotenoids from Microalgae and Seaweeds. Marine Drugs, Volume 14(11), pp. 1-34 
Reichardt, C., 2003. Solvents and Solvent Effects in Organic Chemistry. $4^{\text {th }}$ Edition. Germany: Wiley-VCH Publishers

Rivera, S., Canela, R., 2012. Influence of Sample Processing on the Analysis of Carotenoid in Maize. Molecules, Volume 17, pp. 11255-11268

Rodriguez-Amaya, D.B., Kimura, M., 2004. HarvestPlus Handbook for Carotenoid Analysis. $1^{\text {st }}$ Edition. Washington DC, USA: HarvestPlus

Saini, R.K., Keum, Y.S., 2018. Carotenoid extraction methods: A review of recent developments. Food Chemistry, Volume 240, pp. 90-103.

Shahidan, N., Koy, C.N., Rashidi, O., Ho, L.H., Azrina, I., Nurul Zaizuliana, R.A., N.Z., Zarinah, Z., 2017. The Effect of Time, Temperature and Solid-to-solvent Ratio on Pumpkin Carotenoids Extracted using Food Grade Solvents. Sains Malaysiana, Volume 46(02), pp. 231-237

Sharma, A.K., Sahoo, P.K., Singhal, S., Patel, A., 2016. Impact of Various Media and Organic Carbon Sources on Biofuel Production Potential from Chlorella spp. Biotech, Volume 6(2), pp. 1-12

Shi, J., Mazza, G., Maguer, M.L., 2002. Functional Foods: Biochemical and Processing Aspects. $1^{\text {st }}$ Edition. New York, USA: CRC Press

Tan, P.W., Tan, C.P., Ho, C.W., 2011. Antioxidant Properties: Effects of Solid-to-solvent Ratio on Antioxidant Compounds and Capacities of pegaga (Centella asiatica). International Food Research Journal, Volume 18(2), pp. 557-562

Warkoyo, W., Saati, E.A., 2011. The Solvent Effectiveness on Extraction Process of Seaweed Pigment. Makara Journal of Technology, Volume 15(1), pp. 5-8 